\title{
Injection drug use practices and HIV infection among people who inject drugs in Kigali, Rwanda: a cross-sectional study
}

Jean Olivier Twahirwa Rwema ${ }^{1 *} \mathbb{0}$, Vianney Nizeyimana ${ }^{2}$, Neia M. Prata ${ }^{1}$, Nneoma E. Okonkwo ${ }^{3}$, Amelia A. Mazzei ${ }^{4,5}$, Sulemani Muhirwa², Athanase Rukundo², Lisa Lucas' ${ }^{1}$, Audace Niyigena ${ }^{6}$, Jean Damascene Makuza ${ }^{7,8,9}$, Chris Beyrer ${ }^{1}$, Stefan D. Baral ${ }^{1}$ and Aflodis Kagaba ${ }^{2}$

\begin{abstract}
Background: In Rwanda, epidemiological data characterizing people who inject drugs (PWID) and their burden of HIV are limited. We examined injection drug use (IDU) history and practices, and HIV infection in a sample of PWID in Kigali.

Methods: From October 2019 to February 2020, 307 PWID aged $\geq 18$ were enrolled in a cross-sectional study using convenience sampling in Kigali. Participants completed interviewer-administered questionnaires on IDU history and practices and HIV testing. We used Poisson regression with robust variance estimation to assess IDU practices associated with HIV infection and assessed factors associated with needle sharing in the six months preceding the study.

Results: The median age was 28 years (IQR 24-31); 81\% (251) were males. Female PWID were more likely to report recent IDU initiation, selling sex for drugs, and to have been injected by a sex partner $(p<0.05)$. In the prior six months, heroin was the primary drug of choice for $99 \%$ (303) of participants, with cocaine and methamphetamine also reported by $10 \%$ (31/307) and 4\% (12/307), respectively. In total, 91\% (280/307) of participants reported ever sharing needles in their lifetime and 43\% (133) knew someone who died from a drug-related overdose. HIV prevalence was $9.5 \%$ (95\% Cl 6.6-13.3). Sharing needles at least half of the time in the previous six months was positively associated with HIV infection (adjusted prevalence ratio (aPR) 2.67; 95\% Cl 1.23-5.78). Overall, 31\% (94/307) shared needles and 33\% (103/307) reused needles in the prior six months. Female PWID were more likely to share needles compared to males (aPR 1.68; 95\% Cl 1.09-2.59). Additionally, bisexual PWID (aPR 1.68; 95\% Cl 1.09-2.59), those who shared needles at the first injection (aPR 2.18; 95\% Cl 1.59-2.99), reused needles recently (aPR 2.27; 95\% Cl 1.51-3.43) and shared other drug paraphernalia (aPR 3.56; 95\% Cl 2.19-5.81) were more likely to report recent needle sharing.
\end{abstract}

Conclusion: HIV infection was common in this study. The high prevalence of needle reuse and sharing practices highlights significant risks for onward transmission and acquisition of HIV and viral hepatitis. These data highlight the urgent need for PWID-focused harm reduction services in Rwanda, including syringe services programs, safe injection

Publication history: This manuscript was previously posted on medRxiv. https://doi.org/10.1101/2021.08.05.21261564.

\footnotetext{
*Correspondence: jtwahir1@jhmi.edu
}

${ }^{1}$ Department of Epidemiology, Key Populations Program, Center for Public Health and Human Rights, Johns Hopkins Bloomberg School of Public Health, 615 N Wolfe Street E 7133, Baltimore, MD 21205, USA

Full list of author information is available at the end of the article

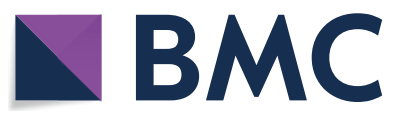

(S) 2021, corrected publication 2022. Open Access This article is licensed under a Creative Commons Attribution 4.0 International License, which permits use, sharing, adaptation, distribution and reproduction in any medium or format, as long as you give appropriate credit to the original author(s) and the source, provide a link to the Creative Commons licence, and indicate if changes were made. The images or other third party material in this article are included in the article's Creative Commons licence, unless indicated otherwise in a credit line to the material. If material is not included in the article's Creative Commons licence and your intended use is not permitted by statutory regulation or exceeds the permitted use, you will need to obtain permission directly from the copyright holder. To view a copy of this licence, visit http://creativecommons.org/licenses/by/4.0/. The Creative Commons Public Domain Dedication waiver (http://creativecommons.org/publicdomain/zero/1.0/) applies to the data made available in this article, unless otherwise stated in a credit line to the data. 
education, naloxone distribution, and substance use disorder treatment programs and optimizing these services to the varied needs of people who use drugs in Rwanda.

Keywords: People who inject drugs, HIV, Injection drug use, Kigali, Rwanda

\section{Introduction}

Globally, 15 million people report injection drug use (IDU), with increasing numbers in countries across subSaharan Africa (SSA) [1, 2]. Estimates of IDU range from 0.13 to $0.62 \%$ among the general adult population in SSA [1]. IDU is associated with an increased risk of acquiring HIV and other sexually transmitted infections (STIs), hepatitis B (HBV), hepatitis C ( $\mathrm{HCV})$, and other bloodborne infections (OBBI), and is associated with increased burden of mental health disorders [2, 3]. The high risk of HIV among PWID can be explained by individual factors like needle sharing, and structural factors including stigma and discrimination, criminalization, high exposure to human rights abuses; and a paucity of harm reduction programs $[4,5]$. These structural-level factors limit PWID engagement in prevention and treatment services, resulting in PWID having poorer HIV outcomes compared to other adults [6]. PWID additionally face significant social and economic challenges, as often demonstrated by their high burdens of homelessness, unstable housing, and incarceration rates [1]. Finally, PWID have overlapping sexual risks with high levels of inconsistent condom use and sex work [7].

While the needs of PWID have been widely explored and documented in high-income countries, limited data exist for countries across SSA [1, 8]. However, a review of IDU in six African countries found a high prevalence of high-risk behaviors including needle sharing and inconsistent condom use among PWID [9]. In addition to the paucity of evidence to guide programming, few PWID-centered programs exist [8]. A systematic review of interventions to prevent and manage HIV and HCV among PWID revealed that while more countries in SSA are studying drug use, few countries have increased the implementation of PWID-focused programs over the last decade ( 2 to 7 for syringe programs, 4 to 8 for opioid substitution therapy, and even fewer for other interventions) [8]. Thus, more research among PWID is needed to guide implementation across SSA.

In Rwanda, HIV prevalence among reproductive aged adults has stabilized at 3\% for the last decade, with the country being one of the few to achieve the UNAIDS 90-90-90 HIV elimination targets by 2020 [10]. However, similar progress has yet to be seen among key populations (KPs). Recent studies have demonstrated a high prevalence of HIV and other STIs and programmatic gaps among KPs including Men who Sex with Men,
Transgender Women, and Female Sex Workers [11-13]. Moreover, PWID have been the most overlooked in HIV programming and research in Rwanda. Rwanda's HIV guidelines have a minimum package of services for both MSM and FSW, but no such program exists for PWID [14]. This lack of PWID-focused national programming, coupled with the criminalization of drug use, further complicates programming in Rwanda [10]. Thus, understanding and addressing the needs of PWID in Rwanda is a public health and human rights imperative.

We conducted this study to inform future research and programming for PWID in Rwanda. The aim of this paper was to estimate the burden of HIV infection and of IDU practices among PWID in Kigali.

\section{Methods}

Study context, procedures, and population

This was a cross-sectional mixed methods study implemented by Health Development Initiative (HDI), a local nongovernmental organization working with KPs in Rwanda. This study leveraged qualitative and quantitative methods to guide implementation of health programs for PWID in Rwanda. The specific objectives were to collect data on sociodemographic characteristics and IDU practices among PWID, to characterize the PWID population, and to provide an estimate of the HIV prevalence among PWID in Kigali.

Given the lack of a sampling frame and nonexistence of reliable epidemiological or program data to guide probability sampling methods for PWID, study participants were recruited through purposive and convenience sampling in Kigali city from October 2019 to February 2020. Initial participants were recruited from clients who use HDI clinical services in Kigali city. HDI offers a range of clinical services to members of different KPs. Clients who reported injecting drugs recently, able, and willing to provide informed consent were recruited into the study. Upon recruitment, these participants were trained and encouraged to recruit their own peers who injected drugs to the study. However, contrary to respondent-driven sampling, there was no maximum number of participants that individuals could recruit. Further community outreach was conducted by HDI community liaisons to recruit more PWID from all three districts of Kigali: Nyarugenge, Kicukiro, and Gasabo. Eligible participants were at least 18 years old, had injected drugs in the six months preceding the study, agreed to be tested for HIV, 
and gave written consent to participate in the study. The study was approved by the Rwanda National Ethics Committee N: 027/RNEC/2020.

\section{Data collection}

Data collection was conducted in two HDI sites in Kigali city. After signing the informed consent form, participants underwent structured face-to-face interviews conducted by trained data collectors and biological testing for HIV. The questionnaire comprised of questions related to sociodemographic characteristics and IDU history and practices in the months preceding the study. Participants were also asked about their need for, and access to, substance use disorder treatment programs. No additional personal identifying information was collected other than the signature on the written informed consent.

We performed HIV rapid testing for all participants who gave consent, per the national guidelines [14]. The screening test was Alere HIV Combo-Determine (Alere, Inc, Waltham, MA), and the confirmatory test was HIV1/2 STAT-PAK (Medford, NY, USA). Participants with a prior documented HIV diagnosis in a health facility were not retested. Participants who were newly found to be living with HIV were referred to a healthcare facility to initiate antiretroviral treatment (ART) and for further medical management. Participants also received information on centers providing substance use disorder treatment in Rwanda. Upon completion of study procedures, participants received $2000 \mathrm{Frw}$ as transport reimbursement.

\section{Outcome assessment}

The primary outcome was prevalent HIV infection. HIVpositive status was based on testing conducted in the study or previously medically confirmed HIV-positive status. The second outcome was self-reported recent needle sharing (i.e., six months prior to study enrollment).

\section{Other variables of interest}

\section{Sociodemographic characteristics}

Sociodemographic characteristics included age, sex assigned at birth, education, occupation, and sexual orientation.

Age was collected as a continuous variable but categorized into three groups for analytical purposes: 18-24, $25-34$, and $\geq 35$ years. Sex was defined as female or male based on sex assignment at birth. Sexual orientation was self-reported and categorized as heterosexual, homosexual, and bisexual. Education and occupation were analyzed as categorical variables with three groups each (Table 1).

\section{IDU history and practices, access to treatment, and other behaviors}

Participants were asked the age at which they first injected drugs, the drug they first injected, source of the drug, and whether they shared needles during their first drug injection. Overall injection history was assessed by estimating the duration of IDU for each participant and lifetime needle sharing history. Participants were also asked if they knew anyone who had died from a drug overdose. Participants were asked detailed questions about their primary drug of injection, other drugs used, and frequency of drug injection in the prior six months. To assess injection frequency, participants were asked the number of times they injected per day, week, month, or year. Frequency of needle sharing, sharing of other injection materials, and needle reuse were assessed using 5 -item scales ranging from never, rarely, half the time, most of the time, and always. Information on injection partnerships (i.e., sex partners, friends, relatives, drug dealer, strangers, or other) and history of exchanging sex for drugs were also captured. Participants were asked about their knowledge and use of substance use disorder treatment programs in Rwanda (Table 2). Finally, participants were asked questions assessing their HIV knowledge, HIV testing history, and condom use during sex.

\section{Analysis}

We calculated crude estimates, including means and proportions, for sociodemographic characteristics, the outcomes of interest, and other covariates. Pearson's Chisquared tests $\left(\chi^{2}\right)$ were used to compare demographic and IDU behaviors by biological sex, and an alpha level of 0.05 was used to attribute statistical significance.

For both outcomes, we applied Lowess smoothed nonparametric regressions to choose appropriate scales for age and duration of injection drug use. For HIV infection, both variables showed an approximately linear association and were analyzed as continuous variables. However, they were not linearly associated with recent needle sharing and thus were analyzed as categorical variables in the models for the second outcome. All other variables were analyzed as binary or categorical variables for both outcomes (Tables 3 and 4).

Bivariable Poisson regression models with robust variance estimation were fitted to compute prevalence ratios (PR) and 95\% confidence intervals (CI) determining the association between sociodemographic factors and IDU practices for both outcomes. Poisson regressions were used because both outcomes were common and log binomial models failed to converge. The final models for both outcomes were constructed using variables that were associated with the outcome if $p<0.1$ in the bivariable 
Table 1 Baseline characteristics of PWID in Kigali, Rwanda, N:307

\begin{tabular}{|c|c|c|c|c|}
\hline Characteristic & $N$ & $\%$ & $\begin{array}{l}\text { Not living with HIV } \\
N(\%)\end{array}$ & $\begin{array}{l}\text { Living with HIV } \\
N(\%)\end{array}$ \\
\hline \multicolumn{5}{|l|}{ Age in years* } \\
\hline $18-24$ & 83 & 27.2 & $80(96.4)$ & $3(3.6)$ \\
\hline $25-34$ & 188 & 61.6 & $167(88.8)$ & $21(11.2)$ \\
\hline$\geq 35$ & 34 & 11.2 & $30(88.2)$ & $4(11.8)$ \\
\hline \multicolumn{5}{|l|}{ Biological sex } \\
\hline Female & 56 & 18.2 & $48(85.7)$ & $8(14.3)$ \\
\hline Male & 251 & 81.8 & $230(91.6)$ & $21(8.4)$ \\
\hline \multicolumn{5}{|l|}{ Education } \\
\hline Primary education or less & 47 & 15.3 & $40(85.1)$ & $7(14.9)$ \\
\hline Some secondary education & 79 & 25.7 & $76(96.2)$ & $3(3.8)$ \\
\hline Completed secondary or above & 181 & 58.9 & $162(89.5)$ & $19(10.5)$ \\
\hline \multicolumn{5}{|l|}{ Marital status** } \\
\hline Single & 252 & 82.9 & $232(92.1)$ & $20(7.9)$ \\
\hline Cohabitating/Married & 33 & 10.8 & $31(93.9)$ & $2(6.1)$ \\
\hline Divorced/Separated/Widow & 19 & 6.3 & $12(63.2)$ & $7(36.8)$ \\
\hline \multicolumn{5}{|l|}{ Occupation } \\
\hline Unemployed & 169 & 55 & $154(91.1)$ & $15(8.9)$ \\
\hline Student & 10 & 3.3 & $10(100)$ & $0(0)$ \\
\hline Part time/Full time employee & 128 & 41.7 & $114(89.1)$ & $14(10.9)$ \\
\hline \multicolumn{5}{|l|}{ Self-reported sexual orientation*** } \\
\hline Heterosexual & 215 & 70.3 & $198(92.1)$ & $17(7.9)$ \\
\hline Homosexual & 35 & 11.4 & $31(88.6)$ & $4(11.4)$ \\
\hline Bisexual & 56 & 18.3 & $48(85.7)$ & $8(14.3)$ \\
\hline
\end{tabular}

* Data missing for $n=2$; **Data missing for $n=3$; *** Data missing for $n=1$

analyses. Sex and age were included in the final multivariable models irrespective of their associations with the outcomes in the bivariable analyses. Analyses were performed with Stata version 14.2 (StataCorp, College Station, TX) statistical package.

\section{Results}

Sociodemographic characteristics and HIV infection

Overall, 322 PWID were recruited, but analyses were restricted to 307 participants for whom HIV status information was available (five participants refused testing and 10 were missing testing results). The median age of participants was 28 years (IQR:24-31), and 81\% (248) were males (Table 1 ).

The prevalence of HIV in this group was 9.5\% (95\% CI 8.7-9.3).

\section{Injection drug use history and practices}

Median age at first injection was 23 (IQR 20-27), but 17\% (53) of participants had their first injection before reaching 18 . The majority of participants, $57 \%$ (176), had been injecting for four or more years. Nearly all, 99\% (304), injected heroin their first time.

In the six months preceding the study, heroin was the primary drug of choice for 99\% (303) of participants. However, 10\% (31) and 4\% (12) also reported injecting cocaine and methamphetamine, respectively. Many participants, 30\% (93), had used a drug combination in the six months before the study. The most common combination of drugs was heroin and marijuana, reported by $23 \%$ (70) of participants, while alcohol use was reported in combination with heroin by $9 \%$ (28). IDU frequency was high with 95\% (293) of participants reporting at least one injection per day in the previous six months.

Overall, 31\% (94) of participants reported recent needle sharing. However, up to $91 \%$ (280) of participants reported ever sharing needles in their lifetimes. Furthermore, 33\% (103) reported reusing needles in the previous six months. Most participants, 98\% (301), reported getting sterile syringes and needles from pharmacies and $20 \%$ (61) reported also getting needles from their networks, including friends and sex partners. However, 34\% (101) of participants reported inconsistent access to sterile needles for injection purposes. 
Table 2 Injecting drug use history and practices among PWID in Kigali, Rwanda, N:307

\begin{tabular}{|c|c|c|c|c|c|}
\hline Variable & $N$ & $\%$ & $\begin{array}{l}\text { Female } \\
N(\%)\end{array}$ & $\begin{array}{l}\text { Male } \\
N(\%)\end{array}$ & $p$ value \\
\hline \multicolumn{6}{|l|}{ First drug injection } \\
\hline \multicolumn{6}{|l|}{ Age at first injection } \\
\hline Less than 18 & 53 & 17.3 & $5(8.9)$ & $48(19.1)$ & \multirow[t]{3}{*}{0.187} \\
\hline $18-24$ & 132 & 43 & $27(48.2)$ & $105(41.8)$ & \\
\hline$>25$ & 122 & 39.7 & $24(42.9)$ & $98(39.1)$ & \\
\hline \multicolumn{6}{|l|}{ Drug injected the first time } \\
\hline Heroin & 304 & 99.1 & $55(98.2)$ & $249(99.2)$ & \multirow[t]{3}{*}{0.454} \\
\hline Cocaine & 2 & 0.6 & $1(1.8)$ & $1(0.4)$ & \\
\hline Methamphetamine & 1 & 0.3 & $0(0)$ & $1(0.4)$ & \\
\hline \multicolumn{6}{|c|}{ Person who performed the injection the first time } \\
\hline Self & 134 & 43.7 & $21(37.5)$ & $113(45.1)$ & \multirow[t]{4}{*}{0.0001} \\
\hline Friend & 146 & 47.5 & $17(30.4)$ & $129(51.4)$ & \\
\hline Sex partner & 20 & 6.5 & $16(28.6)$ & $4(1.6)$ & \\
\hline Other & 7 & 2.3 & $2(3.5)$ & $5(1.9)$ & \\
\hline \multicolumn{6}{|l|}{ Needle sharing the first time } \\
\hline No & 234 & 76.2 & $43(76.8)$ & $191(76.1)$ & \multirow[t]{2}{*}{0.913} \\
\hline Yes & 73 & 23.8 & $13(23.2)$ & $60(23.9)$ & \\
\hline \multicolumn{6}{|l|}{ Source of drug the first time } \\
\hline Bought them from someone & 259 & 84.4 & $38(67.8)$ & $221(88.1)$ & \multirow[t]{4}{*}{0.001} \\
\hline Received them for free & 41 & 13.4 & $16(28.6)$ & $25(9.9)$ & \\
\hline Traded them for sex & 5 & 1.6 & $2(3.6)$ & $3(1.2)$ & \\
\hline Refused to answer & 2 & 0.6 & $0(0)$ & $2(0.8)$ & \\
\hline \multicolumn{6}{|l|}{ Injecting drug history } \\
\hline \multicolumn{6}{|l|}{ Duration of drug injection* } \\
\hline Less than 3 & 129 & 42.3 & $32(58.2)$ & $96(38.6)$ & \multirow[t]{3}{*}{0.007} \\
\hline $4-5$ years & 105 & 34.4 & $18(32.7)$ & $87(34.9)$ & \\
\hline Over 5 & 71 & 23.3 & $5(9.1)$ & $66(26.5)$ & \\
\hline \multicolumn{6}{|l|}{ Needle sharing history } \\
\hline Never shared needles & 27 & 8.8 & $6(10.7)$ & $21(8.4)$ & \multirow[t]{2}{*}{0.575} \\
\hline Ever shared needles & 280 & 91.2 & $50(89.3)$ & $230(91.6)$ & \\
\hline \multicolumn{6}{|l|}{ Used a Drug combination } \\
\hline No & 212 & 69.5 & $45(83.3)$ & $167(66.5)$ & \multirow[t]{2}{*}{0.015} \\
\hline Yes & 93 & 30.5 & $9(16.7)$ & $84(33.5)$ & \\
\hline \multicolumn{6}{|c|}{ Needle sharing in the previous six months } \\
\hline Never & 213 & 69.4 & $39(69.6)$ & $174(69.4)$ & \multirow[t]{3}{*}{0.285} \\
\hline Rarely & 60 & 19.5 & $8(14.3)$ & $52(20.7)$ & \\
\hline Half of the time or more & 34 & 11.1 & $9(16.1)$ & $25(9.9)$ & \\
\hline \multicolumn{6}{|c|}{ Needle reuse in the previous six months } \\
\hline Never & 204 & 66.5 & $45(80.4)$ & $159(63.4)$ & 0.05 \\
\hline Rarely & 75 & 24.4 & $8(14.3)$ & $67(26.7)$ & \\
\hline Half of the time or more & 28 & 9.1 & $3(5.3)$ & $25(9.9)$ & \\
\hline Selling sex for Drugs in the previc & & & & & \\
\hline No & 204 & 68.5 & $22(39.3)$ & $182(75.2)$ & 0.0001 \\
\hline Yes & 94 & 31.5 & $34(60.7)$ & $60(24.8)$ & \\
\hline Need and access to substance use & & & & & \\
\hline Tried to reduce or quit drug cons & & & & & \\
\hline No & 122 & 39.9 & $23(41.1)$ & 99 (39.6) & 0.839 \\
\hline Yes & 184 & 60.1 & $33(58.9)$ & $151(60.4)$ & \\
\hline Aware of any Drug addiction trea & & & & & \\
\hline
\end{tabular}


Table 2 (continued)

\begin{tabular}{|c|c|c|c|c|c|}
\hline Variable & $N$ & $\%$ & $\begin{array}{l}\text { Female } \\
N(\%)\end{array}$ & $\begin{array}{l}\text { Male } \\
N(\%)\end{array}$ & $p$ value \\
\hline No & 205 & 66.7 & $38(67.9)$ & $167(66.6)$ & 0.285 \\
\hline Yes & 45 & 14.7 & $11(19.6)$ & $34(13.5)$ & \\
\hline Don't know & 57 & 18.6 & $7(12.5)$ & $50(19.9)$ & \\
\hline \multicolumn{6}{|c|}{ Drug Addiction treatment in the previous six months**** } \\
\hline No & 290 & 95.4 & $54(96.4)$ & $236(95.2)$ & 0.683 \\
\hline Yes & 14 & 4.6 & $2(3.6)$ & $12(4 . .8)$ & \\
\hline \multicolumn{6}{|c|}{ Unable to access Drug Addiction treatment in the previous six months } \\
\hline No & 259 & 84.4 & $49(87.5)$ & $210(83.7)$ & 0.457 \\
\hline Yes & 48 & 15.6 & $7(12.5)$ & $41(16.3)$ & \\
\hline \multicolumn{6}{|c|}{ Ever enrolled in a Drug Addiction treatment program } \\
\hline Never been treated & 263 & 85.7 & $51(91.0)$ & $212(84.5)$ & 0.395 \\
\hline Ever been treated & 21 & 6.8 & $3(5.4)$ & $18(7.2)$ & \\
\hline Refused to answer & 23 & 7.5 & $2(3.6)$ & $21(8.3)$ & \\
\hline
\end{tabular}

Bold values are for variables that were found to be statistically significantly different between male and female PWID

* Data missing for $\mathrm{n}=2$; ** Data missing for $\mathrm{n}=9$; ${ }^{* *}$ Data missing for $\mathrm{n}=1$; ${ }^{* * *}$ Data missing for $\mathrm{n}=3$

There were several differences in IDU practices between males and females. Females were more likely to have been injected by a sex partner the first time $\left(\chi^{2}\right.$ $p<0.007)$, to have recently initiated IDU $\left(\chi^{2} p<0.007\right)$, and to report selling sex for drugs compared to males $\left(x^{2} p<0.0001\right)$ (Table 2).

Regarding HIV-related knowledge and behavior, 87\% (268) reported knowing that IDU was a risk factor for HIV infection. Over half of participants, 65\% (198), reported inconsistent condom use in the previous six months.

\section{Factors associated with HIV infection}

In the final multivariable model, PWID who reported sharing needles half the time or more in the six months prior to the study were more likely to be living with HIV compared to those who did not share needles (adjusted prevalence ratio (aPR) 2.67; 95\% CI 1.235.78) (Table 3).

\section{Factors associated with recent needle sharing}

In the multivariable analyses, several demographic and IDU variables were associated with recent needle sharing. Female PWID were more likely to share needles during drug injection compared to male PWID (aPR 1.68; 95\% CI 1.09-2.58). Additionally, bisexual individuals (aPR 1.48; 95\% CI 1.03-2.07) were more likely than heterosexual individuals to share needles.

Regarding IDU history and practices, participants who had shared needles during their first injection were more likely to have shared needles recently (aPR 2.18; 95\% CI 1.58-2.99). Furthermore, needle reuse (aPR 2.27; 95\% CI 1.51-3.43) and sharing other drug injection equipment (aPR 3.56; 95\% CI 2.19-5.81) were positively associated with needle sharing (Table 4).

\section{Discussion}

This study is one of the first to characterize the population of PWID in Kigali and to describe the burden of HIV in this community. Moreover, it clearly demonstrates the existence of individual risk factors in this population that are known to be associated with HIV, including needle sharing and inconsistent condom use. These practices highlight substantial potential risks of onward transmission and acquisition of HIV and other blood-borne infections among PWID. These results show an urgent need for implementation of evidence-based harm reduction strategies and other individual-, network-, and structural-level interventions to reduce morbidity and mortality among PWID in Rwanda.

In this convenience-based sample, PWID carried a disproportionate burden of HIV over three times what is observed in the general population [15]. These findings are consistent with other African studies, underscoring the need to address the HIV prevention and treatment needs of PWID [1]. However, some countries have reported higher HIV burden among PWID (e.g., Kenya 14-20\%; Mozambique 20-50\%), likely reflecting the overall higher burden of HIV in these countries compared to Rwanda [16-19]. Injection partners with whom one shares injection equipment often serve as a primary mode of HIV acquisition among PWID. However, risk 
Table 3 Factors associated with HIV infection among PWID in Kigali, Rwanda, N: 307

\begin{tabular}{|c|c|c|c|c|c|c|}
\hline & $\begin{array}{l}\text { N Living } \\
\text { with HIV }\end{array}$ & $\begin{array}{l}\text { \% Living } \\
\text { with HIV }\end{array}$ & Unadjusted PR (95\% Cl) & $p$ value & Adjusted PR (95\% Cl) & $p$ value \\
\hline \multicolumn{7}{|l|}{ Sociodemographic characteristics } \\
\hline Age in years* & & & $1.05(1.01-1.09)$ & 0.02 & $0.98(0.91-1.07)$ & 0.842 \\
\hline \multicolumn{7}{|l|}{ Biological sex } \\
\hline Female & 8 & 14.3 & Ref & & & \\
\hline Male & 21 & 8.4 & $0.58(0.27-1.25)$ & 0.169 & $1.86(0.86-4.04)$ & 0.118 \\
\hline \multicolumn{7}{|l|}{ Education } \\
\hline Primary education or less & 7 & 14.9 & Ref & & Ref & \\
\hline Some secondary education & 3 & 3.8 & $0.25(0.07-0.94)$ & 0.04 & $0.29(0.09-1.04)$ & 0.06 \\
\hline Completed secondary or above & 19 & 10.5 & $0.71(0.31-1.57)$ & 0.395 & $0.64(0.27-1.39)$ & 0.239 \\
\hline \multicolumn{7}{|l|}{ Marital status** } \\
\hline Single & 20 & 7.9 & Ref & & Ref & \\
\hline Cohabitating/Married & 2 & 6.1 & $0.76(0.18-3.13)$ & 0.708 & $0.75(0.21-2.74)$ & 0.67 \\
\hline Divorced/Separated/Widow & 7 & 36.8 & $4.64(2.25-9.58)$ & 0.001 & $3.86(1.49-10.01)$ & 0.005 \\
\hline \multicolumn{7}{|l|}{ Occupation } \\
\hline Unemployed & 15 & 8.9 & Ref & & & \\
\hline Employed & 14 & 10.9 & $1.23(0.62-2.46)$ & 0.554 & & \\
\hline \multicolumn{7}{|l|}{ Self-reported sexual orientation*** } \\
\hline Heterosexual & 17 & 7.9 & Ref & & & \\
\hline Homosexual & 4 & 11.4 & $1.44(0.52-4.05)$ & 0.484 & & \\
\hline Bisexual & 8 & 14.3 & $1.81(0.82-3.97)$ & 0.141 & & \\
\hline \multicolumn{7}{|c|}{$\begin{array}{l}\text { Drug Injection related behaviors, access to needles and } \\
\text { condom use }\end{array}$} \\
\hline \multicolumn{7}{|l|}{ Age at first injection } \\
\hline Before 18 years & 5 & 9.4 & Ref & & & \\
\hline 18 to 24 years & 12 & 9.1 & $1.36(0.57-3.23)$ & 0.48 & & \\
\hline Over 25 years & 12 & 9.8 & $1.82(0.75-4.37)$ & 0.183 & & \\
\hline \multicolumn{7}{|l|}{ Duration of drug injection**** } \\
\hline Years injecting drugs & & & $1.06(0.99-1.11)$ & 0.055 & $1.04(0.92-1.18)$ & 0.494 \\
\hline \multicolumn{7}{|c|}{ Needle sharing in the previous 6 months } \\
\hline Never & 15 & 7.1 & Ref & & Ref & \\
\hline Rarely & 6 & 10 & $1.42(0.57-3.51)$ & 0.447 & $1.31(0.44-3.93)$ & 0.625 \\
\hline Half the time or more & 8 & 23.5 & $3.34(1.53-7.28)$ & 0.002 & $2.77(1.28-5.98)$ & 0.009 \\
\hline \multicolumn{7}{|c|}{$\begin{array}{l}\text { Number of needles sharing partners in the previous } \\
6 \text { months }\end{array}$} \\
\hline None & 7 & 11.1 & Ref & & & \\
\hline One to two & 15 & 8.2 & $0.74(0.31-1.73)$ & 0.484 & & \\
\hline Three or more & 7 & 15.9 & $1.43(0.54-3.79)$ & 0.471 & & \\
\hline \multicolumn{7}{|c|}{ Selling sex for drugs in the previous 6 months***** } \\
\hline No & 16 & 7.8 & Ref & & & \\
\hline Yes & 13 & 13.8 & $1.76(0.88-3.52)$ & 0.108 & & \\
\hline \multicolumn{7}{|l|}{ Access to sterile needles } \\
\hline Always & 20 & 10.2 & Ref & & & \\
\hline Sometimes & 9 & 8.9 & $0.87(0.41-1.85)$ & 0.723 & & \\
\hline \multicolumn{7}{|l|}{ Condom use } \\
\hline Always & 10 & 9.2 & Ref & & & \\
\hline Never or sometimes & 19 & 9.6 & $1.04(0.50-2.17)$ & 0.904 & & \\
\hline
\end{tabular}

Bold values are for variables that were found to be significantly associated with prevalent HIV infection

${ }^{*}$ Data missing for $\mathrm{n}=2$; ${ }^{* *}$ Data missing for $\mathrm{n}=3$; ${ }^{* *}$ Data missing for $\mathrm{n}=1$; ${ }^{* * *}$ Data missing for $\mathrm{n}=2$; **** Data missing for $\mathrm{n}=9$ 
Table 4 Factors associated with needle sharing in the six months preceding the study among PWID in Kigali, Rwanda, N: 307

\begin{tabular}{|c|c|c|c|c|c|}
\hline & $\begin{array}{l}\text { Shared needles } \\
\%(N)\end{array}$ & Unadjusted PR (95\% Cl) & $p$ value & Adjusted PR (95\% Cl) & $p$ value \\
\hline \multicolumn{6}{|l|}{ Sociodemographic characteristics* } \\
\hline $18-24$ & $22.9(19)$ & Ref & & Ref & \\
\hline $25-34$ & $32.9(62)$ & $1.44(0.92-2.25)$ & 0.108 & $1.01(0.71-1.42)$ & 0.978 \\
\hline$>35$ & $38.2(13)$ & $1.67(0.93-2.99)$ & 0.084 & $0.91(0.57-1.45)$ & 0.698 \\
\hline \multicolumn{6}{|l|}{ Biological sex } \\
\hline Male & $30.7(77)$ & Ref & & Ref & \\
\hline Female & $30.4(17)$ & $0.98(0.64-1.53)$ & 0.963 & $1.68(1.09-2.59)$ & 0.019 \\
\hline \multicolumn{6}{|l|}{ Education } \\
\hline Primary education or less & $23.4(11)$ & Ref & & & \\
\hline Some secondary education & $21.5(17)$ & $0.92(0.47-1.79)$ & 0.805 & & \\
\hline Completed secondary or above & $36.5(66)$ & $1.56(0.89-2.71)$ & 0.116 & & \\
\hline \multicolumn{6}{|l|}{ Marital status** } \\
\hline Single & $29.7(75)$ & Ref & & & \\
\hline Cohabitating/Married & $33.3(11)$ & $1.12(0.66-1.88)$ & 0.669 & & \\
\hline Divorced/Separated/Widow & $36.8(7)$ & $1.24(0.66-2.31)$ & 0.501 & & \\
\hline \multicolumn{6}{|l|}{ Occupation } \\
\hline Unemployed & $25.4(43)$ & Ref & & Ref & \\
\hline Employed/ Student & $36.9(51)$ & $1.45(1.03-2.04)$ & 0.031 & $1.58(1.19-2.11)$ & 0.002 \\
\hline \multicolumn{6}{|l|}{ Self-reported sexual orientation*** } \\
\hline Heterosexual & $27.4(59)$ & Ref & & Ref & \\
\hline Homosexual & $28.6(10)$ & $1.04(0.58-1.84)$ & 0.889 & $1.08(0.75-1.55)$ & 0.667 \\
\hline Bisexual & $44.6(25)$ & $1.63(1.13-2.34)$ & 0.009 & $1.46(1.03-2.07)$ & 0.034 \\
\hline \multicolumn{6}{|c|}{ Drug Injection related behaviors, access to needles and condom use } \\
\hline \multicolumn{6}{|l|}{ Age at first injection } \\
\hline Before 18 years & $30.2(16)$ & Ref & & & \\
\hline 18 to 24 years & $33.3(44)$ & $1.10(0.68-1.78)$ & 0.683 & & \\
\hline Over 25 years & $27.9(34)$ & $0.92(0.56-1.52)$ & 0.754 & & \\
\hline \multicolumn{6}{|l|}{ Duration of drug injection ${ }^{* * * *}$} \\
\hline Less than 3 years & $20.3(26)$ & Ref & & Ref & \\
\hline $4-5$ years & $30.5(32)$ & $1.50(0.95-2.35)$ & 0.077 & $1.05(0.74-1.48)$ & 0.791 \\
\hline Over 5 years & $50.7(36)$ & $2.49(1.65-3.77)$ & 0.001 & $1.25(0.83-1.89)$ & 0.281 \\
\hline \multicolumn{6}{|l|}{ Needle sharing at the first injection } \\
\hline No & $15.4(36)$ & Ref & & Ref & \\
\hline Yes & $79.5(58)$ & $5.16(3.73-7.13)$ & 0.001 & $2.18(1.59-2.99)$ & 0.001 \\
\hline \multicolumn{6}{|l|}{ Needle reuse in the previous 6 months } \\
\hline No & $9.8(20)$ & Ref & & Ref & \\
\hline Yes & $71.8(74)$ & $7.32(4.74-11.31)$ & 0.001 & $2.27(1.51-3.43)$ & 0.001 \\
\hline \multicolumn{6}{|c|}{ Number of needles sharing partners in the previous 6 months } \\
\hline Two or less & $21.9(54)$ & Ref & & Ref & \\
\hline More than two partners & $90.9(40)$ & $4.14(3.21-5.34)$ & 0.001 & $0.99(0.79-1.25)$ & 0.983 \\
\hline \multicolumn{6}{|c|}{ Selling sex for drugs in the previous 6 months $s^{* * * *}$} \\
\hline No & $24(49)$ & Ref & & Ref & \\
\hline Yes & $42.5(40)$ & $1.77(1.26-2.48)$ & 0.001 & $1.08(0.79-1.46)$ & 0.607 \\
\hline \multicolumn{6}{|l|}{ Access to sterile needles } \\
\hline Always & $19.4(38)$ & Ref & & Ref & \\
\hline Sometimes & $52.5(53)$ & $2.71(1.92-3.81)$ & 0.001 & $1.10(0.84-1.44)$ & 0.477 \\
\hline \multicolumn{6}{|c|}{ Sharing other drug paraphernalia in the previous 6 months } \\
\hline No & $19.4(38)$ & Ref & & Ref & \\
\hline Yes & $52.5(53)$ & $9.38(6.19-14.21)$ & 0.001 & $3.56(2.19-5.81)$ & 0.001 \\
\hline
\end{tabular}

Bold values are for variables that were found to be significantly associated with needle sharing in the six months prior to the study

* Data missing for $n=2$; ${ }^{* *}$ Data missing for $n=3$; *** Data missing for $n=1$; **** Data missing for $n=2$; ***** Data missing for $n=9$ 
of HIV and OBBI among PWID can be further compounded by sexual risk behaviors (e.g., condomless sex). Our results suggest that consistent condom use in this population is low, which is expected given that research suggests riskier sexual practices are associated with substance abuse [20]. Globally, studies indicate that sexual risks are elevated among PWID in countries across SSA relative to other regions, highlighting the importance of understanding the intersecting impact of sexual and injection drug risks among PWID in Rwanda [1]. Implementing sexual health programs, like condom distribution and HIV/STI management, could mitigate the added sexual risks that PWID face. Successes of the Rwandan HIV program in the general adult population could be leveraged to develop initiatives tailored to PWID needs.

Importantly, we observed a high prevalence of risky IDU practices. A high proportion of participants reported reusing needles, which is known to be associated with severe infections including abscesses, septicemia, and infective endocarditis [21-23]. We also found that nine out of ten participants reported ever sharing needles, while over one-third reported sharing needles in the prior 6 months. Consistent with existing literature, needle sharing was positively associated with HIV infection in this study $[16,17,19]$. Taken together, these data demonstrate the urgency for implementing comprehensive harm reduction interventions in Rwanda, particularly syringe service programs (SSP), to provide sterile injection equipment and education on safer injection techniques [24]. Through provision of sterile needles and other drug paraphernalia, SSPs have been shown to effectively reduce unsafe injection practices and injection frequency, to facilitate linkage to substance use disorder treatment programs including medications for opioid use disorder (MOUD) programs, and to be cost-effective [25-27]. Notably, we have found that female PWID, bisexual individuals, PWID who shared needles during their first injection, those who reused needles recently, and those that share other drug injection paraphernalia had higher proportions of needle sharing compared to others. Consequently, careful consideration of these factors will be needed for optimal SSPs in Rwanda.

In addition to SSPs, there is a necessity for overdose prevention and treatment of substance use disorders in Rwanda. Despite naloxone already being available in some pharmacies in Rwanda [28], nearly half of participants reported knowing someone who died from a drugrelated overdose. This calls for immediate introduction of overdose prevention and treatment programs and strategies to optimize distribution and use of naloxone in Kigali. Community-based overdose prevention and response programs have been implemented in other settings, and there is evidence that these programs can save lives [29-31]. Finally, over half of participants reported wanting to reduce or quit drug injection practices; however, only $15 \%$ reported ever attending a substance use treatment program, highlighting a need for increased coverage and availability of programs such as MOUD. Heroin was the primary drug of choice, as observed in other countries in the region [2]. Additionally, some participants reported injecting cocaine and methamphetamine. It is possible that there are more drug types being used in Kigali that are not reported in this study, most likely because participants were not asked about them during interviews. Given the high frequency of injection reported (i.e., most participants injected daily) and the likely high number of overdoses, a comprehensive study evaluating the types of drugs available in Kigali and their chemical composition is needed to inform programming for PWID in Kigali.

Another contribution of this study is characterizing the demographic characteristics of PWID in Kigali by age, sex assigned at birth, and sexual orientation. Almost one-fifth of participants reported their first injection before age 18. The 2020 World Drug Report highlighted the growing demand for injection drugs, particularly among young adults across African countries [2,32]. This is evidenced by the fact that almost half of participants in our study reported injecting drugs for fewer than 3 years. This was especially the case for female PWID who were more likely to have recently initiated IDU. Additionally, although there was no statistical association between biological sex and HIV infection, female PWID in our study reported a higher prevalence of selling sex for drugs consistent with other studies among female PWID [33, 34]. PWID who also report sex work are at a higher risk of HIV acquisition compared to other PWID [7]. Furthermore, one in three female PWID was injected by a sexual partner the first time they injected a drug, which demonstrates the complex interplay of sexual and IDU practices. Sex differences in the risk of HIV and other infectious diseases acquisition among PWID have been documented in other settings [34, 35]. Finally, these data also show that sexual orientation is an important consideration in PWID programming in Rwanda. One in ten PWID and nearly one in five selfidentified as MSM and bisexual, respectively. Members of sexual minority groups are known to be at a higher risk for both intersecting stigmas as well as the acquisition of HIV and other STIs in Rwanda [12]. Thus, there is a need for further studies detailing social and health experiences of different demographic subgroups of PWID including female PWID and sexual and gender minorities who use drugs. PWID programs should also be cognizant of the complex interplay of sexual 
identities and sexual and IDU practices to offer optimal interventions to all members of KP groups.

Our study has several limitations. First, our sample is convenience-based. We are therefore unable to make inferences to the larger PWID population in Kigali or Rwanda. Furthermore, the cross-sectional nature of the study limits our ability to make temporal inferences between the variables of interest and HIV infection. Second, separate from HIV testing, our measurers are selfreported and may be subject to recall or social desirability bias. However, we observed high prevalence of injection and needle sharing behaviors, thus providing a benchmark with which to inform programmatic planning for PWID in Rwanda. Our study was also limited in that it did not collect information on the behaviors of injection partners. The importance of injection drug networks on the transmission and acquisition of blood-borne infections, including HIV, and the social diffusion of behaviors and other network norms, have been well documented in other settings [36]. Our finding that half of participants reported injecting with someone else at first injection, indicates the potential for implementing network-based interventions to reach PWID with services and educational messages early in their injection history. Finally, while the study identifies a proportion of the sample that are aware of their HIV status, we are unable to determine HIV outcomes further downstream of the HIV care continuum, including antiretroviral uptake and viral suppression. In particular, viral suppression could serve as a marker to gauge the success of HIV treatment programs in this population. The lack of HBV and HCV testing in this study presents another limitation given the high burden of these infections among PWID globally [1]. Despite these limitations, our study provides critical information to understand the HIV programming needs of PWID in Kigali.

Future research should leverage respondent-driven sampling, or other sampling approaches used to reach and estimate the size of historically hidden populations without a known sampling frame [37, 38]. Stronger sampling approaches could facilitate data collection for larger epidemiological studies, enabling estimation of the prevalence of HIV, HBV, HCV, and other health (e.g., viral suppression) and social outcomes (e.g., mental health), as well as the impact of structural factors (e.g., stigma, criminalization) on these outcomes at the community or population level. Estimating the size of the PWID population would allow for better programmatic planning to address the HIV and other health needs of PWID in Rwanda.

\section{Conclusion}

The findings of this study call for immediate action. PWID have a high prevalence of HIV and self-reported injection practices associated with substantial onward risk of transmission and acquisition of HIV and other blood-borne infections. Implementation of evidencebased comprehensive harm reduction programs is not only a public health emergency but also a human rights and moral imperative. As of 2021, few African countries have adopted syringe services programs, and even fewer have government-led comprehensive harm reduction services in place. The data presented here suggest that Rwanda should join this list to save lives of people who use drugs and building the evidence base to support implementation across the African continent.

\section{Acknowledgements \\ We are grateful to all study participants for their time and for sharing their personal histories with us.}

\section{Authors' contributions}

VN, AAM, SM, AR, AK, AN conceived the study. SM, VN, AK led the implementation of the study. JOTR, NPM, NO analyzed the data. JOTR wrote the first draft of the paper. All authors read and approved the final manuscript.

\section{Funding}

This study was internally funded by HDI resources. JOTR is supported in part by the 2021 Institute of International Education Centennial Fellowship and the Desmond M. Tutu Scholarship at Johns Hopkins University. CB is supported in part by the Desmond M. Tutu Professorship at Johns Hopkins University. NPM's effort is supported through T32 NRSA Pre-doctoral Training Fellowship in HIV Epidemiology and Prevention Sciences (5T32Al102623-08) within the Johns Hopkins University Center for Public Health and Human Rights. SB's is supported in part by a grant from the National Institutes of Mental Health (R01MH110358).

\section{Data availability}

The data are owned by the partner institutions. Requests for data utilization should be sent to Aflodis Kagaba at: kagaba@hdirwanda.org.

\section{Declarations}

\section{Competing interests}

The authors have no competing interests to disclose.

\section{Author details}

${ }^{1}$ Department of Epidemiology, Key Populations Program, Center for Public Health and Human Rights, Johns Hopkins Bloomberg School of Public Health, 615 N Wolfe Street E 7133, Baltimore, MD 21205, USA. ${ }^{2}$ Health Development Initiative, Kigali, Rwanda. ${ }^{3}$ School of Medicine, Johns Hopkins University, Baltimore, MD, USA. ${ }^{4}$ Emory University School of Medicine, Atlanta, GA, USA. ${ }^{5}$ Projet San Francisco, Kigali, Rwanda. ${ }^{6}$ Département de Psychiatrie, Service d'addictologie, Hôpitaux Universitaire de Genève, Geneva, Switzerland. ${ }^{7}$ School of Population and Public Health, University of British Columbia, Vancouver, BC, Canada. ${ }^{8}$ BC Center for Disease Control, Vancouver, BC, Canada. ${ }^{9}$ Rwanda Biomedical Center, Kigali, Rwanda. 
Received: 28 September 2021 Accepted: 30 November 2021

Published: 15 December 2021

\section{References}

1. Degenhardt L, Peacock A, Colledge S, Leung J, Grebely J, Vickerman P, et al. Global prevalence of injecting drug use and sociodemographic characteristics and prevalence of HIV, HBV, and HCV in people who inject drugs: a multistage systematic review. Lancet Glob Health. 2017;5(12):e1192-207.

2. World Drug Report 2020. 2021.

3. Grebely J, Larney S, Peacock A, Colledge S, Leung J, Hickman M, et al. Global, regional, and country-level estimates of hepatitis $C$ infection among people who have recently injected drugs. Addiction. 2019;114(1):150-66.

4. Jürgens R, Csete J, Amon JJ, Baral S, Beyrer C. People who use drugs, HIV and human rights. The Lancet. 2010;376(9739):475-85.

5. WHO. ATLAS on substance use 2017: resources for the prevention and treatment of substance use disorders. Geneva: World Health Organization; 2017.

6. Malta M, Ralil da Costa M, Bastos Fl. The paradigm of universal access to HIVtreatment and human rights violation: how do we treat HIV-positive people who use drugs? Curr HIV/AIDS Rep. 2014;11(1):52-62.

7. Campeau L, Blouin K, Leclerc P, Alary M, Morissette C, Blanchette C, et al. Impact of sex work on risk behaviours and their association with HIV positivity among people who inject drugs in Eastern Central Canada: crosssectional results from an open cohort study. BMJ Open. 2018;8(1):e019388.

8. Larney S, Peacock A, Leung J, Colledge S, Hickman M, Vickerman P, et al. Global, regional, and country-level coverage of interventions to prevent and manage HIV and hepatitis C among people who inject drugs: a systematic review. Lancet Glob Health. 2017;5(12):e1208-20.

9. Dewing S, Plüddemann A, Myers BJ, Parry CDH. Review of injection drug use in six African countries: Egypt, Kenya, Mauritius, Nigeria, South Africa and Tanzania. 2009. https://doi.org/10.1080/09687630500480228

10. UNAIDS. 2020 Global AIDS update — seizing the moment-tackling entrenched inequalities to end epidemics. UNAIDS; 2020.

11. Twahirwa Rwema JO, Lyons CE, Herbst S, Liestman B, Nyombayire J, Ketende $\mathrm{S}$, et al. HIV infection and engagement in HIV care cascade among men who have sex with men and transgender women in Kigali, Rwanda: a cross-sectional study. J Int AIDS Soc. 2020;23(S6):e25604.

12. Twahirwa Rwema JO, Herbst S, Hamill MM, Liestman B, Nyombayire J, Lyons CE, et al. Cross-sectional assessment of determinants of STIs among men who have sex with men and transgender women in Kigali, Rwanda. Sex Transm Infect. 2021:sextrans-2020-054753.

13. Ingabire R, Parker R, Nyombayire J, Ko JE, Mukamuyango J, Bizimana J, et al. Female sex workers in Kigali, Rwanda: a key population at risk of HIV, sexually transmitted infections, and unplanned pregnancy. Int J STD AIDS. 2019:30(6):557-68.

14. Health Mo. National Guidelines for Prevention and Management of HIV. Kigali, Rwanda: Ministry of Health—Rwanda Biomedical Center, HIV \& AIDS SaOD; 20182016

15. NISR. Rwanda Demographic and Health Survey 2014-15-Final Report. Kigali - Rwanda: National Insitute of Statistics of Rwanda 2016.

16. Baltazar CS, Horth R, Boothe M, Sathane I, Young P, Langa DC, et al. High prevalence of HIV, HBsAg and anti-HCV positivity among people who injected drugs: results of the first bio-behavioral survey using respondentdriven sampling in two urban areas in Mozambique. BMC Infect Dis. 2019;19(1):1-13

17. Kurth AE, Cleland CM, Des Jarlais DC, Musyoki H, Lizcano JA, Chhun N, et al. HIV prevalence, estimated incidence, and risk behaviors among people who inject drugs in Kenya. J Acquir Immune Defic Syndr. 2015;70(4):420.

18. Tun W, Sheehy M, Broz D, Okal J, Muraguri N, Raymond HF, et al. HIV and STI prevalence and injection behaviors among people who inject drugs in Nairobi: results from a 2011 bio-behavioral study using respondent-driven sampling. AIDS Behav. 2015;19(1):24-35.

19. Scheibe A, Young K, Moses L, Basson RL, Versfeld A, Spearman CW, et al. Understanding hepatitis $B$, hepatitis $C$ and HIV among people who inject drugs in South Africa: findings from a three-city cross-sectional survey. Harm Reduct J. 2019;16(1):1-11.

20. Brookmeyer KA, Haderxhanaj LT, Hogben M, Leichliter J. Sexual risk behaviors and STDs among persons who inject drugs: a national study. Prev Med. 2019:126:105779.
21. Wurcel AG, Anderson JE, Chui KK, Skinner S, Knox TA, Snydman DR, et al editors. Increasing infectious endocarditis admissions among young people who inject drugs. Open forum infectious diseases. Oxford: Oxford University Press; 2016

22. Tan C, Shojaei E, Wiener J, Shah M, Koivu S, Silverman M. Risk of new bloodstream infections and mortality among people who inject drugs with infective endocarditis. JAMA Netw Open. 2020;3(8):e2012974.

23. Wright $T$, Hope V, Ciccarone D, Lewer D, Scott J, Harris M. Prevalence and severity of abscesses and cellulitis, and their associations with other health outcomes, in a community-based study of people who inject drugs in London, UK. PLoS ONE. 2020;15(7):e0235350.

24. Drugs UNOo, Crime INoPWUD, Joint United Nations Programme on HIV/ AIDS. Implementing comprehensive HIV and HCV programmes with people who inject drugs: practical guidance for collaborative interventions. United Nations Office on Drugs and Crime Vienna; 2017.

25. Strathdee SA, Celentano DD, Shah N, Lyles C, Stambolis VA, Macalino G, et al. Needle-exchange attendance and health care utilization promote entry into detoxification. J Urban Health. 1999;76(4):448-60.

26. Hagan H, McGough JP, Thiede H, Hopkins S, Duchin J, Alexander ER. Reduced injection frequency and increased entry and retention in drug treatment associated with needle-exchange participation in Seattle drug injectors. J Subst Abuse Treat. 2000;19(3):247-52.

27. Riley ED, Kral AH, Stopka TJ, Garfein RS, Reuckhaus P, Bluthenthal RN. Access to sterile syringes through San Francisco pharmacies and the association with HIV risk behavior among injection drug users. J Urban Health. 2010;87(4):534-42.

28. Health RMo. National list of essential medicines for adults 6 th edition. Kigali, Rwanda2015.

29. Bennett AS, Bell A, Tomedi L, Hulsey EG, Kral AH. Characteristics of an overdose prevention, response, and naloxone distribution program in Pittsburgh and Allegheny County, Pennsylvania. J Urban Health. 2011:88(6):1020-30.

30. Leece PN, Hopkins S, Marshall C, Orkin A, Gassanov MA, Shahin RM. Development and implementation of an opioid overdose prevention and response program in Toronto, Ontario. Can J Public Health. 2013;104(3):e200-4.

31. Clark AK, Wilder CM, Winstanley EL. A systematic review of community opioid overdose prevention and naloxone distribution programs. J Addict Med. 2014;8(3):153-63.

32. DRUGS UNOO, LABOR. WORLD DRUG REPORT 2020 (SET OF 6 BOOKLETS): UN; 2021.

33. Atkinson J, McCurdy S, Williams M, Mbwambo J, Kilonzo G. HIV risk behaviours, perceived severity of drug use problems, and prior treatment experience in a sample of young heroin injectors in Dar es Salaam, Tanzania. Afr J Drug Alcohol Stud. 2011;10(1):1-9.

34. Jain JP, Abramovitz D, Strathdee SA, Gonzalez-Zuniga P, Rangel G, West BS, et al. Sex work as a mediator between female gender and incident HIV infection among people who inject drugs in Tijuana, Mexico. AIDS Behav. 2020;24(9):2720-31.

35. Des Jarlais DC, McKnight C, Feelemyer J, Arasteh K, Tross S, Campbell AN, et al. Heterosexual male and female disparities in HIV infection at the end of an epidemic: HIV infection among persons who inject drugs in New York City, 2001-2005 and 2011-2015. Drug Alcohol Depend. 2018;185:391-7.

36. Ghosh D, Krishnan A, Gibson B, Brown SE, Latkin CA, Altice FL. Socia network strategies to address HIV prevention and treatment continuum of care among at-risk and HIV-infected substance users: a systematic scoping review. AIDS Behav. 2017;21(4):1183-207.

37. Heckathorn DD. Respondent-driven sampling II: deriving valid population estimates from chain-referral samples of hidden populations. Soc Probl. 2002;49(1):11-34

38. Heckathorn DD, Wangroongsarb P, Thwing J, Eliades J, Satimai W, Delacollette C, et al. Respondent-driven sampling: a new approach to the study of hidden populations. Soc Probl. 1997:44(2):174-99.

\section{Publisher's Note}

Springer Nature remains neutral with regard to jurisdictional claims in published maps and institutional affiliations. 